\title{
Science Academies' Refresher Course in Statistical Physics
}

\author{
Organized by \\ Sir P T Sarvajanik College of Science, Surat \\ 18-30 December 2017 \\ Sponsored by \\ Indian Academy of Sciences, Bengaluru \\ Indian National Science Academy, New Delhi \\ The National Academy of Sciences, India, Allahabad
}

The Course is aimed at college teachers of statistical physics at BSc/MSc level. It will cover basic principles and techniques, in a pedagogical manner, through lectures and tutorials, with illustrative problems. Some advanced topics, and common difficulties faced by students will also be discussed. College/University teachers, with at least a masters degree in Physics/Mathematics/Engineering are encouraged to apply.

Topics: There will be six courses dealing with, Basic principles and general theorems, Probability theory and applications of statistical physics, Quantum statistical physics and Bose-Einstein condensation, Markov processes and Computer simulations, Critical phenomena and renormalization group theory, introduction to non-equilibrium statistical physics.

Resource Persons: Sriram Ramaswamy (IISc, Bangalore), Kavita Jain (JNCASR, Bangalore), Debashish Chowdhury (IIT, Kanpur), Kushal Shah (IISER, Bhopal), Sanjib Sabhapandit (RRI, Bangalore), Sanjay Puri (JNU, Delhi).

Teachers/research scholars who wish to participate should send a short letter explaining their reasons for wanting to participate, along with brief curriculum vitae (including name, date of birth, gender, educational qualifications, teaching experience, typical courses taught, positions held, postal and email address, and contact numbers).

Applications are to be submitted ONLINE by clicking the following link:

http://web-japps.ias.ac.in: 8080/Refreshcourse/RSTZ.jsp

Course Director: Prof. Deepak Dhar. A printed copy of the application approved by the Head of the Institution to be sent to the Course Coordinator: Dr. Pruthul Desai. (pruthulrcsp@gmail.com) Department of Physics, Sir P. T. Sarvajanik College of Science, Athwalines, Surat, Gujarat 395001.

Selected participants will be provided local hospitality. Outstation participants will be reimbursed round trip 3-tier train fare (shortest route) from place of residence. Participants are expected to stay for the full duration of the course.

Last date for receipt of application: October 10, 2017 